\title{
Developing Organizational Adaptability for Complex Environment
}

\author{
Steven A. Boylan \\ Associate Professor \\ United States Army Command \& General Staff College (CGSC) \\ Kenneth A. Turner \\ Curriculum Developer \\ United States Army Command \& General Staff College (CGSC)
}

\section{Introduction}

War is an environment where cause and effect is often indiscernible, where traditional responses often fail, and solving problems requires new ways of thinking. In this environment, the need for adaptability in leaders and organizations is essential. The challenges presented by the complex and uncertain environment dictates that one of the essential qualities for success, as a leader, is the ability to develop organizations capable of adapting.

We are approaching complexity from two perspectives, the complexity of the operating environment which is well established (Seijts, Billou, \& Crossan, 2010; Vasconcelos \& Ramirez, 2011; Collinson \& Jay, 2012; Dervitsiotis, 2012; Haynes, 2015) and the complexity of the organization. The complexity of the organization is not well established in literature.

Traditionally, leadership theories view organizations as machines with processes, sub-elements and resources that leaders analyze, disassemble, and reassemble in new and improved structures. This is an antiquated, industrial age perspective. A more effective view of organizations is as complex organic living systems (Wheatley, 2006; Goldstein, Hazy, \& Lichtenstein, 2010). As a complex system, an organization can adapt and grow, as a machine cannot. Another important aspect of viewing an organization as a complex system is that a small group of people can make a major difference beyond the scope of their individual capacity (Goldstein, Hazy, \& Lichtenstein, 2010). By accepting that organizations are complex, and by definition inherently capable of adapting, leaders can take positive action to set the conditions to enhance organizational adaptability.

Developing organizations capable of adapting requires leaders to set conditions. Setting conditions normally requires purposeful activities by the leadership to foster and develop leader and individual adaptability, supported by processes and activities that enable adaptive behaviors through the totality of the organization (Goldstein, Hazy, \& Lichtenstein, 2010). Developing adaptive organizations is challenging, requiring both art and process. In this paper, we touch on both and provide a concept for developing military organizations capable of adapting to changing environments and setting the conditions for organizational adaptability.

In 2013, the Army Chief of Staff General Raymond Odierno (Chief Operating Officer equivalent), established developing "adaptive Army leaders for a complex world" as the Army's number one strategic priority (Odierno, 2013, p.2). Emphasizing this point, while associating the 
need for adaptability to overcome the challenges of modern warfare, General Odierno asserted that the Army must, "Educate and develop all Soldiers and Civilians to grow the intellectual capacity to understand the complex contemporary security environment to better lead Army, Joint, Interagency, and Multinational task forces and teams" (Odierno, 2013, p. 3). In addition to the Chief of Staff's focus on adaptability, one of the Army's principles of leader development is "Train to develop adaptive leaders" (Adamshick, 2013, p. 30).

In 2014, the Army's headquarters responsible for training and future concepts reaffirmed the importance of adaptability in the Army Operating Concept (AOC), elevating adaptability to the level of a core tenet and one of the core competencies for generating combat power. The AOC described how future Army forces conduct operations as part of larger forces to deter conflict, prevail in war, and succeed in a wide range of contingencies in the future operational environment. The concept described the importance of a variety of cognitive skills and activities associated with individual adaptability. "Army leaders think critically, are comfortable with ambiguity, accept prudent risk, assess the situation continuously, develop innovative solutions to problems, and remain mentally and physically agile to capitalize on opportunities" (Department of the Army, 2014, p. 21). One of the salient points in the concept is the need for adaptive leaders. "What all Army operations will have in common is a need for innovative and adaptive leaders and cohesive teams that thrive in conditions of complexity and uncertainty" (Department of the Army, 2014, p. 16). The Army Operating Concept clearly establishes the importance of adaptability for success in complex environments.

The Army Operating Concept and the Army Chief of Staff's public statements focus on individual adaptability without providing the methodology for developing organizations capable of adapting (Adamshick, 2013; Odierno, 2013). While the Army Operating Concept introduces the idea of adaptability in units, Army doctrine fails to address how leaders develop organizational adaptability. The lack of doctrine presents a challenge. The complex environment of today and the future suggest an important quality of effective leadership is fostering organizational adaptability. How do organizational leaders develop organizations capable of adapting in the volatile, uncertain, complex, and ambiguous environment envisioned by senior leaders? There is inadequate theory and literature on how leaders develop organizations capable of adapting. Army literature focuses on the complexity of the operational environment and developing a mindset for adapting at the individual level, neglecting organizational adaptability (Army Doctrine Publication 1, 2012; Army Doctrine Publication 3-0, 2011; Army Doctrine Publication 5-0, 2012; Department of the Army, 2014; Odierno 2013; Department of the Army, 2001). Literature focusing on business or civilian organizations examines individual adaptability without clearly focusing on organizational adaptability. It is our opinion the civilian literature focuses more on learning organizations avoiding in-depth examination of organizational adaptability.

The recent call for leaders who can adapt to the complexities of warfare should not be a surprise to anyone. The nature of military operations since September 2001 has reinforced the requirement for adaptive organizations. A 2012 Joint and Coalition Operational Analysis decade of war study team in the Department of Defense (DOD) reviewed 46 studies from 2003 to the beginning of 2012, examining over 400 separate findings observations and best practices. The research team reported eleven strategic themes from this effort. The fifth theme focused on 
adaptation. The research team found, "In the course of operations, especially in the first half of the decade following 9/11, DOD policies, doctrine, training, and equipment were often poorly suited to operations other than major combat, forcing widespread and costly adaptation, and in the process, threatening the mission" (Decade of War Vol.I, p 19, 2012). We assert the Department of Defense recognizes an inability to prepare and train for every eventuality, acknowledging the need for adaptive organizations.

The Army has recognized the importance of individual adaptability for success in complex contemporary security environments for more than a decade. The Army characterizes war as complex, uncertain, rapidly changing, and ambiguous (Army Doctrine Publication 1, 2012; Army Doctrine Publication 3-0, 2011; Army Doctrine Publication 5-0, 2012; Department of the Army, 2014; Odierno 2013). In 2001, The Objective Force White Paper called for leaders who "...will be adaptive and self-aware, able to master transitions in the diversity of $21{ }^{\text {st }}$ Century military operations" (Department of the Army, 2001, p. v). Throughout the document, the paper stressed the importance of adaptive and self-aware leaders. In 2002, The Army Training and Leader Development Panel Study (ALTDS) whose purpose was to identify skill sets required of members of the Army, determined that for success in the complex wars of the future, Army leaders must be self-aware and adaptive (Department of the Army, 2002).

In addition to the U.S. Army recognizing the importance of individual adaptability, civilian leadership literature also praises its merits. Recognizing the immense pace of change in the business environment, many managers recognize the importance of individual adaptability (Burke \& Cooper, 2000; Dess \& Picken, 2000; Heifetz \& Linsky, 2002; Heifetz, Grashow, \& Linsky, 2009; Yukl \& Mahsud, 2010,). Bennis (2003) also recognizes the importance of individual adaptability when he uses the term adaptive capacity. According to Bennis (2003), leaders with adaptive capacity can work through difficult events, gain strength, and important insights from their experiences. Bennis (2003) posited that adaptive capacity is the "key competence," indicating that adaptive capacity is "absolutely essential for leaders" (p. xxvi). Bennis (2003) further describes adaptive capacity as the ability to "respond quickly and intelligently to relentless change." Adaptive capacity is a kind of creativity that enables leaders to see solutions to problems and rapidly put into motion the activities to make it happen (Bennis, 2003). Hiefetz, Grashow, and Linsky (2009) view adaptive capacity significantly different. They describe adaptive capacity as a form of resilience of the people and the systems in an organization to withstand the pressures and discomfort inherent in change (Hiefetz, Grashow, \& Linsky 2009).

\section{Defining Adaptability}

A review of the literature reveals there is not a widely accepted definition of adaptability. Researchers at the Institute of Defense Analysis (IDA) defined adaptability as, "...the degree to which adjustments are possible in practices, processes, or structures to projected or actual changes in climate. Adaptation can be spontaneous or planned and be carried out in response to or in anticipation of changes in conditions" (Tillson, et al., 2005, p. 5). In 2005, the Army Research Institute (ARI) defined adaptability, “....as an effective response to an altered situation" (White et al., 2005, p. 2). Yukl and Mahsud (2010) contend that adaptive leadership involves changing individual behaviors in the "appropriate ways as the situation changes" (p. 81). Army 
doctrine states that adaptability requires leaders who think critically and creatively, are comfortable with ambiguity, accept prudent risk, and can adjust rapidly to the environment while continuing to assess the situation. It specifically defines adaptability as the capacity to "respond to changing threats and situations with appropriate, flexible, and timely actions" (Department of the Army Doctrine Reference Publication 6-22, 2012, p. 9-5).

Hiefetz, Grashow, and Linsky (2009) published the influential work The Practice of Adaptive Leadership that, in our opinion, does not precisely define adaptability for the purpose of this paper. Hiefetz, Grashow, and Linsky (2009) use the term adaptability throughout the work, yet do not provide a specifically defined, precise term for adaptability. Hiefetz, Grashow, and Linsky (2009) approach adaptability differently by providing characteristics of adaptive leadership by stating, "Adaptive leadership is specifically about change that enables the capacity to thrive" and "Adaptive leadership is the practice of mobilizing people to tackle tough challenges and thrive" ( $p$ 14). Hiefetz, Grashow, and Linsky (2009) link adaptive leadership to the biological concept of a thriving organism and equate thriving to increased growth and value of the organization.

The definitions above share several characteristics. First, they all involve a change in behavior. Secondly, there is an expectation that this behavioral change is appropriate for the situation. Finally, with the exception of Heifetz, Gashow, and Linsky (2009), the definitions characterize adaptation as a reactive response to changes in the environment.

While there are similarities in the definitions, there are also gaps. The definitions do not explicitly include innovation, creativity, or a proactive element. We think these elements should be part of a comprehensive definition. Other sources provide additional ideas that deserve consideration in a more comprehensive definition. The Army Operating Concept (Department of the Army, 2014) explicitly uses innovation in discussing adaptability and Bennis (2003) associates creativity with his idea of adaptive capacity. The inclusion of the term 'projected' in the definition provided by Tillson et al., (2005) suggests that adaptability is proactive in nature. Projected implies proactive actions, but does not clearly describe adaptability as proactive. The omission of innovation, creativity, and the ability to anticipate change reveals gaps in the definitions, which is significant. We posit innovation, creativity, and the ability to anticipate change are important in developing new ways to solve problems and should be part of a comprehensive definition of adaptability.

Although the literature does not provide a widely accepted definition of individual adaptability, we propose a more comprehensive and useful definition. Adaptability is a change in behavior characterized by innovative or creative approaches in anticipation of, or response to, environmental changes appropriate to solve problems. Adaptability is both proactive and reactive. From our perspective, an adaptive leader anticipates problems and develops alternative solutions to a wide range of possible outcomes while assessing and responding to the everchanging environment.

Individual Adaptability. Individual adaptability is a mindset and a cognitive ability. It is a way of thinking, how a leader confronts challenges, or views change. It requires improvisation and experimentation (Heifetz, Grashow \& Linsky, 2009). IDA proposes a model 
that describes individual adaptability as a function of the cognitive skills of intuition and critical and creative thinking, coupled with the relational skills of self-awareness and social skills (Tillson, et al, 2005). IDA reviewed several studies and found these abilities were common to individuals who adapted successfully to changing circumstance. IDA concluded these skills enable individuals to adapt effectively to the unforeseen challenges inherent in the current operational environment. (See figure one)

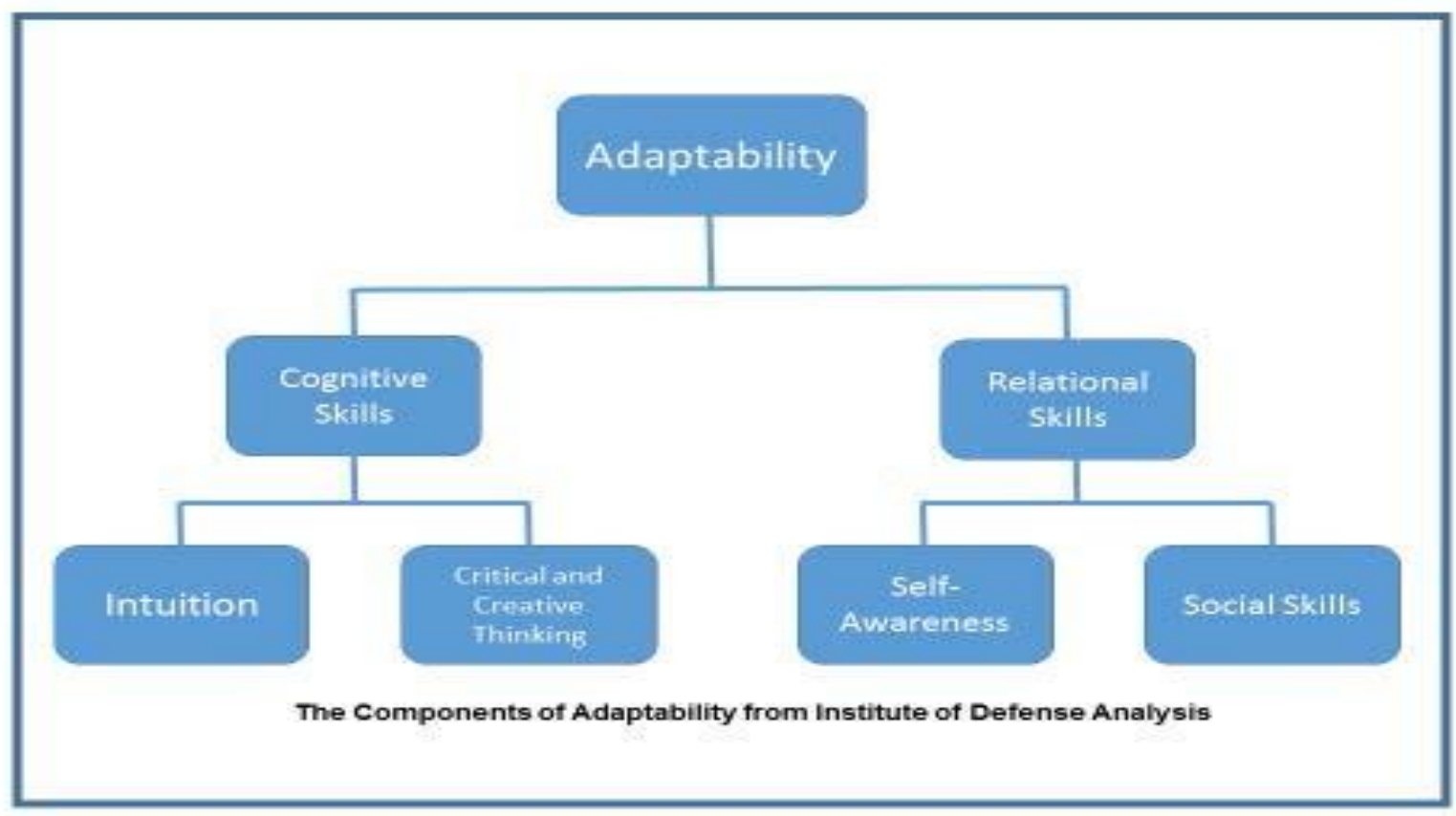

Figure 1. The Components of Adaptability by Tillson, J. C. F., et al. (2005). Learning to respond to asymmetric threats, IDA Document number D-3114, Alexandria, VA, Institute for Defense Analysis, August, p. 40.

In 2002, ATLDS preceded the IDA findings by contending that for success in the complex wars of the future, Army leaders must be self-aware and adaptive. The ATLDS called for Army leaders to develop what it termed "enduring competencies" of self-awareness and adaptability, and linked the two competencies in a symbiotic relationship asserting, "Selfawareness without adaptability is a leader who cannot learn to accept change and modify behavior brought about by changes to his environment. Adaptability without self-awareness is irrationally changing for change sake, not understanding the relationship between abilities, duties, and the environment" (Department of the Army, 2002, p. OS-3). The study called on leaders to assess their weakness in adapting to a complex operational environment, correct this shortfall, and adapt by recognizing changes in the operational environment.

Individual leader adaptability is an essential step in creating organizational adaptability, but individual adaptability is not enough to guarantee organizational adaptability. This is similar to what Senge (2006) and (Goldstein, Hazy, \& Lichtenstein, 2010) observed when they posited that individual learning and group learning do not assure organizational learning or adaptability. 
Organizational adaptability requires purposeful action on the part of the leader to instill an adaptive mindset in the organization. As Goldstein asserts, the complexity of organizations provides an inherent capacity for adaptability. Successful leaders capitalize on this inherent capacity.

Organizational Adaptability. One of the insights from the IDA and ARI studies is the importance of a mindset for adaptability, which includes an open mindedness to expect and accept change. Organizational adaptability is a derivative of organizational change. Organizational adaptability can be a planned or unplanned change; however, to foster planned organizational change a planned method or framework is required to modify the functioning of an organization (Kotter, 2012; Lippitt, 1958). Either leaders setting the tone for change agents or as the change agents themselves must established the climate that overcomes resistance from other members of their organization and encourages them to adopt new practices (Beer \& Nohira, 2000; Kanter, 1983; Van de Ven, 1986). Leaders implement change within organizations by applying social influence through modification of attitudes or behaviors of the organizational members (Battilana \& Casciaro, 2012).

Organizational adaptability is not a physical component. Organizational adaptability is an attitude that must pervade the organization. Organizational adaptability is about setting expectations for the individual and the organization to adjust to the ever-changing environment (Tillson, et al, 2005), and mobilizing followers to overcome challenges and improve the organization (Heifetz, Grashow \& Linsky 2009). The organizational leader must create the organizational climate and attitude to foster "ambidextrous" organizations - meaning an organization that can complete the objectives of today while simultaneously envisioning the problems of tomorrow in a volatile, uncertain, complex, and ambiguous world. Organizations capable of performing both of these seemingly conflicting tasks will excel in the complexity of today and in the uncertainty of the future (Battilana \& Casciaro, 2012; Harvard Business School, 2003).

It is not enough for leaders to be individually adaptive. Individual adaptability does not automatically transfer to organizational adaptability. Adaptability is a multidimensional construct that encompasses a range of cognitive skills and behaviors that leaders develop in themselves and inculcate in their organizations through education, training, and experience. Developing organizations capable of adapting requires active leadership that fosters a culture that values collective adaptability. Leaders who establish rigid and inflexible organizational systems, processes, and activities stifle adaptive and creative individuals by suppressing new ideas and change (Battilana \& Casciaro, 2012; Harvard Business School, 2003). To capitalize on individual adaptability, leaders must develop organizations that can adapt to the ever-changing environment. An organization capable of adapting is one that can both anticipate and react to changes in the environment (Klein \& Pierce, 2001). Adaptable organizations have an organizational mindset that values change, accepts new ideas, and demonstrates this mindset in both planning and execution. Creating the capacity for adaptability in organizations is about setting the conditions in the organizational climate that transforms the culture by establishing processes and habits that encourage both proactive and reactive activities during execution. 


\section{Characteristics of Organizational Adaptability}

Harvard Business School (2003) described six characteristics that promote creativity and innovation in organizations. These include: risk taking is acceptable to management, new ideas and new ways of doing things are welcome, information is free flowing and not controlled by managers, employees have access to knowledge sources, good ideas are supported by patrons, and innovators are rewarded (Harvard Business School, 2003). While the authors propose these characteristics to promote creativity and innovation, we propose there is a strong relationship between innovation, creativity, and adaptability. Because of this strong relationship, we modified and combined the six characteristics into four characteristics and applied them to organizational adaptability.

We assert leaders develop organizational adaptability by fostering an organizational culture where accepting and taking prudent risk is commonplace, considering new ideas is customary, promoting collaboration enables the free flow of ideas, and supporting good ideas and rewarding individual adaptability is routine (Garvin, Edmondson, Gino, 2008; Harvard Business School, 2003). Leaders develop organizational adaptability through their behaviors, activities, organizational systems, and processes that foster these four characteristics.

Accepting and Taking Prudent Risk. One of the characteristics of organizations with high levels of adaptability is the way individuals view risk. Leaders have to accept risk-taking and the members of the organization have to understand acceptable levels of risk. Organizations with high levels of adaptability have leaders and individuals that are comfortable with assuming prudent risk. Another aspect of accepting and taking prudent risk is the emotional element of psychological safety.

Psychological safety plays an important role in assuming prudent risk. Psychological safety is the establishment of practices and shared beliefs within the organizations that encourage open and trustful relationships that facilitates candid discussions without the fear of rejection or reprisals (Baer \& Frese, 2003; Carmeli \& Gittell, 2009). Understanding mistakes will occur with experimentation, leaders that establish an environment of psychological safety encourage innovation, experimentation, and willingness to take risk (Goldstein, Hazy, \& Lichtenstein, 2010; Kessel, Krantzer, \& Schultz, 2012).

Assessing prudent risk entails a cost-benefit analysis. Assessing prudent risk requires a leader to apply judgment to weigh the cost of the event toward the benefit gained (Department of the Army Doctrine Reference Publication 6-0, 2012). Identifying prudent risk also requires leaders to implement a process that includes a systemic evaluation of risk in the organization that considers member input. Since many people are naturally risk averse, the wise leader understands that progress is often dependent on assuming prudent risks. It is rare that an organization can progress while avoiding risk. Effective leaders understand the relationship between risk and rewards, and communicate that it is acceptable to take prudent risks to achieve progress. Through this communication, leaders ensure the members of the organization understand that prudent risk is acceptable (Harvard Business School, 2003). Leaders must also 
clearly articulate what is unacceptable risk to subordinates and other members of the organization.

Defining, understanding, and accepting prudent risk is an important and often contentious issue in the Army. Lieutenant General Robert Caslen while discussing risk asked, "How do we foster a culture that allows open dialog between commanders regardless of rank?" (Senior Leadership Conference notes, September 27, 2010). Fostering a culture that allows open dialogue requires the senior leader to initiate the conversation about risk. Organizational leaders must set the conditions for the discussions to occur between and among other leaders and subordinates. Adaptable organizations foster a climate where open dialogue is the norm and the senior leader bears the ultimate responsibility for setting the condition for this climate. The senior leader must provide clear guidance on what is prudent risk. He or she cannot leave it up to the subordinate to ask to discuss issues of risk. The leader must reach down, set conditions, create opportunities for discussion, and look for teachable moments to mitigate risk. Among the ways leaders mitigate risk and promote organizational adaptability is by articulating the differences between misconduct, mistakes, and incompetence. Articulating the difference provides clarity to subordinates about leader expectations, which reduces misunderstanding and uncertainty, ultimately encouraging initiative. The dialogue between senior and subordinate helps set the conditions for underwriting mistakes, which contributes to psychological safety.

Considering New Ideas. Much like in accepting prudent risk, psychological safety plays a prominent role in the generation of new ideas and consideration of new ideas. Psychological safety is positively linked to learning from failures (Carmelli \& Gittell, 2009). To cultivate a climate of psychological safety that generates new ideas without the fear of failure, it is essential for leaders to not dismiss seemingly unreasonable solutions to problems and not marginalize members who make mistakes or experiment with new ideas (Heifetz, Gershow \& Linsky, 2009).

An organizational culture that inhibits the development and acceptance of new ideas can impede organizational adaptability. When members of an organization believe leaders will reject their ideas without consideration, they may not develop new ideas, stifling creativity, innovation, and initiative. If the group possesses a strong culture of shared beliefs about how to do business, the introduction of new ideas into the organization can be problematic. If the current way of doing business is working, individuals may be reluctant to adopt new ideas. This inhibits an organization's ability to adapt, grow, and innovate (Schein, 2010).

To be fair, leaders cannot accept all new 'great ideas' from organizational members. Some ideas are not appropriate for the organization's current operating environment. At times, new ideas may not nest with the overall organizational objectives or resource constraints may prohibit the acceptance of all good ideas (Baumann \& Stieglitz, 2013). On the other hand, the complexity of the organization offers opportunities for adaptability for the leader who is perceptive enough to see the potential in deviations from the norm (Goldstein, Hazy, \& Lichtenstein, 2010). Often the complex nature of organizations result in what Goldstein, Hazy, and Lichtenstein (2010) calls "fluctuations." Fluctuations are new ideas that are different from what the organization routinely generates (Goldstein, Hazy, \& Lichtenstein, 2010). The perceptive leader is able to take advantage of these new ideas and not discount them as outside standard practices. These leaders reinforce the new ideas that possess greater potential for 
innovation and improving the organization (Goldstein, Hazy, \& Lichtenstein, 2010). The complexity of an organization can be a boon to adaptability if the leader is perceptive enough to consider the new ideas generated by the fluctuations.

The challenges for leaders are to ensure that the reality of resources and standardized procedures do not prevent the development of new ideas, limiting organizational adaptability. The leadership must establish an environment where surfacing new ideas is a matter of normal practice. It is incumbent on the leadership to explain to the organization why or why not the ideas are accepted. This transparency encourages the free flow of information, fostering new ideas and new ways of doing business.

Promoting Collaboration. Collaboration includes the free flow of information throughout the organization and the access to knowledge inside and outside the organization. One of the critical enablers for developing organizational adaptability is the development of an organizational climate that facilitates the candid exchange of information vertically and laterally, combined with the capacity to analyze current information and apply it to future problems. Leaders must develop an atmosphere that encourages open-mindedness, innovation, critical thinking, and creative thinking. Highly adaptive organizations are characterized by an environment where no issue is too sensitive to discuss (Heifetz, Grashow \& Linsky, 2009).

An organization that has free flowing information, a free exchange of ideas, and access to information, internally and externally, fosters an environment that can inspire new thinking and generate new ideas. Using information from various sources, that may or may not seem connected, can lead to creativity and innovative ideas (Harvard Business School, 2003).

Organizations that fail to adapt are typically hierarchical organizations where information is not readily available, is often controlled, and limited to those that believe they have a need or right to know (Harvard Business School, 2003). Leader centric organizations often foster environments that focus the attention on the leader's ideas instead of the collective knowledge of the group (Raelin, 2011). This type of environment precludes opportunities for communication and limits opportunities for critical and creative thinking and innovation (Harvard Business School, 2003). The traditional, command structure or "classic bureaucracy of the industrial age" characterized by rigid rules and procedures, often hinders information flow, collaboration and ultimately adaptability (Raelin, 2011). Organizations that demonstrate high levels of adaptability and create solutions have a favorable balance between centralized and decentralized control (Wheatley, 2006). Organizations that can rapidly adapt have enough centralization to facilitate the gathering of data from the lower echelons, are able to synthesize the data and then coordinate the different elements for appropriate action (Klein \& Pierce, 2001). In the complexity of the current operational environment, rigid structures are inadequate to meet the demands of the everchanging, complex situation.

Promoting collaboration is the senior leader's responsibility. The leader sets the conditions for open dialogue, which allows candor and presenting alternative views. Despite this responsibility, owing to the complexity and volatility of the operational environment, leaders must often rely on subordinates to raise issues that may indicate an impending problem or impending risk. To encourage the surfacing of issues, leaders should also set conditions that 
encourage respectful dissent. Leaders need to encourage the discussion of views that conflict with their own perspective to achieve a clearer picture of the operational environment.

Organizations capable of adapting consist of multi-discipline members who collaborate by sharing information and rapidly solving problems (Raelin, 2011; McChrystal, 2015). Organizations capable of adapting have more experience solving problems than non-adaptive organizations. The experience provides a wider base of options to consider when facing problems. Members of adaptive organizations have developed problem solving routines, processes, and activities that facilitate assessing problems and developing sound solutions. Members share this experience through collaboration to other less experienced members.

Adaptive organizations also have more latitude due to fewer internal restrictions. The higher the degree of freedom, combined with the other adaptive characteristics can result in more flexibility for the organization (Klein \& Pierce, 2001). Leaders have to ensure those subordinates with pertinent information have the opportunity, ability, and confidence to raise issues. Leaders have to set the conditions that allow the voicing of diverse opinions. Leaders must encourage thoughtful disagreement and seek those individuals that tell them where they and their organization are failing. Questions to encourage open collaboration outside the organization include; who have we talked to about this? Whom else can we talk to about this problem? With whom have we not discussed this?

Collaboration inherently links to the characteristic of organizational adaptability; accepting prudent risk. Collaboration helps organizations identify risk, anticipate change, and adapt to the changing conditions. Much like setting the conditions for having discussions on risk, senior leaders have to provide opportunities for collaboration. This is the opportunity for the leader to ask important questions, take a pause, and consider the operating environment. Are we doing this the right way? Can we do this? Do we have the proper resources? Are we taking on more than we can accomplish? Will this achieve our objective?

Collaboration offers an opportunity to question assumptions and reframe the problem. Operating in a complex environment is inherently risky. The characteristics of the future operating environment magnify that risk, but an adaptive organization with a culture that values collaboration, can help mitigate this risk.

Supporting Good Ideas and Rewarding Individual Adaptability. A positive characteristic of organizations with high levels of adaptability is how leaders and members of the organization accept and support new ideas or new ways of doing business (Harvard Business School, 2003). Often leaders do not have all the answers to challenges facing their organizations. Organizations capable of adapting, value ideas from all levels of the organization and leaders establish systems to ensure those ideas rise to the surface for implementation (Heifetz, Grashow \& Linsky 2009). Since many new ideas emerge from the fringes of acceptable policies and procedures, it is critical for leaders to reward members who develop new ideas. The encouragement of this experimentation contributes to developing adaptive organizations (Goldstein, Hazy, \& Lichtenstein, 2010). 
Organizational leaders must recognize and reward good ideas when they find them. Rewards can take many forms including intrinsic or extrinsic rewards, such as providing necessary resources to implement the idea, providing moral support for the individual that produced the idea, and providing coaching for the individual to implement the idea.

Leaders adjust the weight of the reward commensurate with the effects of the proposal to achieve superior results (Essawi \& Tilchen, 2014). Rewarding creativity produces more creativity and innovation that fosters organizational adaptability. Regardless of the type of reward, research found that those organizations that reward innovative ideas demonstrate more adaptive behaviors than organizations that ignore innovative ideas (Harvard Business School, 2003).

\section{Recognizing Organizational Adaptability}

How do we know if an organization is adaptable? The simple answer is the organization's members successfully anticipate changes or respond to changes to meet the fluctuations of a shifting environment. However, it is more complicated than that. Organizations demonstrate their adaptability in both planning and execution.

Organizations demonstrate their adaptability in planning by proactively anticipating problem areas during development of plans. They accept that the plan is a point of departure for execution and not an immutable path to the end state. Organizations demonstrate their proactive adaptability in planning by developing options during the planning process that anticipate the non-linearity of the operating environment. By expecting change and developing a variety of options, organizations are better able to reduce the reaction time to changes in the environment. Organizations capable of adapting also avoid sunk cost fallacies that may cause them to stick to the plan past the point of no return (Klein \& Pierce, 2001).

While planning to anticipate change is important, the definitive measure of an organization's adaptability is in execution. Adaptive organizations respond to the changing situation by assessing the situation and developing feasible solutions to the problem (Klein \& Pierce, 2001). An example of adaptability in execution is the Cable News Network's, (CNN) response to the World Trade center attack. Immediately following the attack on September 11, 2001, CNN quickly and adeptly demonstrated organizational adaptability. CNN rapidly modified its scheduling and restructured its organization to manage the new demands of the changed environment. Furthermore, the CEO made a significant decision that shifted the mental models of how the organization operated. Because of the seriousness of the situation, the CEO cancelled commercials to adapt the news cycle to the changing information environment, demonstrating incredible organizational adaptability (Deverell \& Olsson, 2010). Without recognizing a change in the environment, it is improbable that an organization will effectively adapt to the change.

The attitude towards change is another important factor demonstrated by organizations with high levels of adaptability. As simple as it sounds, the mindset to expect change and to expect to make adjustments after execution begins is important to adapting. Conversely, those 
organizations that become too committed to "fighting the plan" are routinely rigid, lacking adaptability, and less effective in complex environments.

Essential to assessing a changing environment is the continuous development of situational understanding. Without recognizing a change in the environment, it is improbable that an organization will effectively adapt to the change (Klein \& Pierce, 2001). Sometimes organizations fail to adapt because of "paradigm blindness" (Wheatley, 2006). These organizations refuse to accept the data laid out in front of them because it does not align with their worldview. For example, in the summer of 2005, FEMA refused to accept much of the evidence pointing to the catastrophic effect a category 3 or 4 hurricane would have on New Orleans. The leadership either ignored the data or discounted it as unlikely (Wheatley, 2006). Deverell and Olsson (2010) posited organizations unable to recognize the changes in the environment narrowly focus their efforts on technical aspects of the problem, failing to appreciate the complexity of the changing environment. Organizations with high levels of adaptability routinely reassess and reframe the problem (Klein, Pliske, Crandall, \& Woods, 1999). Members of the organization regularly share information with key individuals to ensure a shared understanding internally and externally to the organization, creating a common picture that facilitates adapting to changing circumstances. Adaptive organizations stay focused on the "big picture." Focusing on the big picture assists the leader's understanding of the relationship between actions within the environment and how those actions influence the end state (Klein \& Pierce, 2001).

\section{Conclusion}

Developing organizations capable of adapting in a dynamic operating environment is an essential competency of organizational leaders and a critical function of successful organizations. Individual adaptability, while important, is not enough to assure organizational success; it can be transitory and fleeting. Leaders must develop organizational adaptability through fostering a supportive command climate where accepting and taking prudent risk is commonplace, new ideas receive valid consideration, collaboration and the free flow of ideas are typical, and rewarding individual adaptability become part of the organization's culture. Adaptive organizations respond to the changing situation by assessing the situation and developing feasible actions to succeed. Adaptable organizations are responsive to change, but also proactively plan for changing conditions. The definitive measure of an organization's adaptability is its success in a changing environment.

We think the continued focus by the Army on adaptability for the future is partially a result of a renewed appreciation that warfare is non-linear and complex. Adaptability is not solely a skill for the future; it is a skill for today. Despite technological advancements and evolution of methods, the human dimension of war remains constant.

The expected volatility, uncertainty, complexity, and ambiguity of the environment will only increase the need for adaptability. The challenges of today and the inherent uncertainty of the future make the development of organizations that can adapt to changing conditions paramount to an organization's success. The leaders who can learn, be comfortable with the unexpected, and adapt to changing circumstances will be the leaders who excel in the future. 
Today's challenges require leaders to adapt individually and develop organizations comfortable with adapting to change. Leaders must develop adaptable organizations that do not expect or pursue certainty, but can thrive in uncertainty and disorder. The organization that can adapt most effectively will be the organization that prevails. The complex challenges of today and the future suggest that an essential quality of effective organizational leadership is fostering organizational adaptability.

\section{References}

Adamshick, M. (2013). "2013 Chief of Staff of the Army leader development task force final Report," Washington D.C. : Headquarters Department of the Army.

Bennis, W. (2003). On becoming a leader, New York, NY: Basic Books

Baer, M., \& Frese, M. (2003). Innovation is not enough: Climates for initiative and psychological safety, process innovations, and firm performance. Journal of Organizational Behavior, 24(1), 45-68. doi: http://dx.doi.org/10.1002/job.179

Baumann, O., \& Stieglitz, N. (2014). Rewarding value-creating ideas in organizations: The power of low-powered incentives. Strategic Management Journal, 35(3), 358-375. doi: http://dx.doi.org/10.1002/smj.2093

Battilana, J., \& Casciaro, T. (2012). Change agents, networks, and institutions: A contingency theory of organizational change. Academy Of Management Journal, 55(2), 381-398. doi: http://dx.doi.org/10.5465/amj.2009.0891

Beer, M., \& Nohria, N. (2000). Cracking the code of change. Harvard Business Review, 78(3), 133-141.

Burke, R. J. (2004). Leading in turbulent times: Managing in the new world of work. Malden Massechusettes: Blackwell.

Carmeli, A \& Gittell, J. H. (2009). High-quality relationships, psychological safety, and learning from failures in work organizations. Journal of Organizational Behavior, 30, 709-729. doi: $10.1002 /$ job.565

Collinson, S., \& Jay, M. (2012). From complexity to simplicity: Unleash your organization's potential. New York, NY: Palgrave MacMillian.

Decade of War Volume I (2012). Enduring lessons from the past decade of operations. Joint and Coalition Operational Analysis (JCOA). The Joint Staff, Washington, D.C. Retreived from https://publicintelligence.net/jcoa-decade-of-war-vol-1/ 
Department of the Army. (2001). Concepts for the objective force. Washington D.C., Chief of Staff.

Department of the Army. (2014). The U.S. Army operating concept; Win in a complex world, 2020-2040. Pamphlet 525-3-1, Headquarters, United States Training and Doctrine Command. Fort Eustis, VA.

Department of the Army. (2002). The Army training and leader development panel report. Office of the Chief of Staff, Washington D. C.

Department of the Army Doctrine Publication 1. (2012). The Army. Washington, D.C.

Department of the Army Doctrine Publication 3-0. (2011). Unified land operations. Washington, D.C.

Department of the Army Doctrine Publication 5-0. (2012). The operations process. Washington, D.C.

Department of the Army Doctrine Reference Publication 6-0. (2012). Mission command. Washington, D.C.

Department of the Army Doctrine Reference Publication 6-22. (2012). Army leadership. Washington, D.C.

Dervitsiotis, K. N. (2012, November). An innovation-based approach for coping with increasing complexity in the global economy. Total Quality Management \& Business Excellence, 23(9-10), 997-1011. doi:10.1080/14783363.2012.728849

Dess, G. G. \& Picken, J. C. (2000). Changing roles: Leadership in the $21^{\text {st }}$ century, Organizational Dynamics, 28 (3), 18-33. doi:http://dx.doi.org/10.1016/S00902616(00)88447-8

Deverell, E., \& Olsson, E. (2010). Organizational culture effects on strategy and adaptability in crisis management. Risk Management, 12(2), 116-134. doi: http://dx.doi.org/10.1057/rm.2009.18

Essawi, M., \& Tilchin, O. (2014). An integrated approach to promoting innovation in an organization. International Journal of Business and Management, 9(7), 70-77. doi: http://dx.doi.org/10.5539/ijbm.v9n7p70

Garvin, D. A., Edmondson, A. C., \& Gino, F. (2008). Is yours a learning organization?. Harvard Business Review, 86(3), 109.

Goldstein, J., Hazy, J. K., \& Lichtenstein, B. B. (2010). Complexity and the nexus of leadership: Leveraging nonlinear science to create ecologies of innovation. New York, NY: Palgrave MacMillian. 
Harvard Business School. (2003). Managing creativity and innovation. Boston, MA: Harvard Business School Press.

Haynes, P. (2015). Managing complexity in the public services (2nd ed.). New York, NY: Routledge.

Heifetz, R., Grashow, A., \& Linsky, M. (2009). The practice of adaptive leadership. Harvard Business Review Press, Boston Mass.

Heifetz, R., Grashow, A., \& Linsky, M. (2009). Leadership in a (permanent) crisis. Harvard Business Review, (July), 64-69.

Heifetz, R., \& Linsky, M. (2002). Leadership on the line: Staying alive through the dangers of leading. Harvard Business School Press, Boston Mass.

Kanter, R. M. (1983). The change masters: Corporate entrepreneurs at work. New York: Simon $\&$ Schuster.

Kessel, M., Kratzer, J., \& Schultz, C. (2012). Psychological safety, knowledge sharing, and creative performance in healthcare teams. Creativity \& Innovation Management, 21(2), 147-157. doi: http://dx.doi.org/10.1111/j.1467-8691.2012.00635.x

Klein, G., Pliske, R. M., Crandall, B., \& Woods, D. (1999). Features of problem detection. Proceedings of the Human Factors and Ergonomics Society Annual Meeting, 43(3), 133-137. doi: http://dx.doi.org/10.1177/154193129904300301

Klein, G. A. \& Pierce, L. (2001). Adaptive teams. Washington, D.C.: Headquarters Department of the Army. Retrieved fromwww.dtic.mil/cgi-bin/GetTRDoc?AD=ADA467743

Kotter, J. (2012). Leading change. Harvard Business Review Press. Boston, Mass.

Lippitt, R. (1958). The dynamics of planned change. New York: Harcourt Brace.

McChrystal, S. (2015). Team of teams: New rules of engagement for a complex world. Instaread.

Odierno, R. (2013, October 16). CSA strategic priorities. Chief of Staff of the Army waypoint two briefing. Washington D. C.: Headquarters, Department of the Army. 211. doi: http://dx.doi.org/10.1177/1742715010394808

Schein, E. H. (2010). Organizational culture and leadership (4th ed.). San Francisco: JosseyBass.

Seijts, G., Billou, N., \& Crossan, M. (2010, May). Coping with complexity. Ivey Business Journal. Retrieved from http://iveybusinessjournal.com/publication/coping-withcomplexity/ 
Senge, P. M. (2006). The fifth discipline: The art \& practice of the learning organization. New York: Currency Doubleday.

Tillson, J. C. F., et al. (2005). Learning to respond to asymmetric threats, (IDA document Number D-3114), Alexandria, VA, Institute for Defense Analysis, August. Retrieved from http://www.dtic.mil/dtic/tr/fulltext/u2/a442427.pdf

Vasconcelos, F. C., \& Ramirez, R. (2011, March). Complexity in business environments. Journal of Business Research, 64(3), 236-241.

doi:10.1016/j.jbusres.2009.11.007

Wheatley, M. J. (2006). Leadership and the new science: Discovering order in a chaotic world (3rd ed.). San Francisco, CA: Berrett-Koehller.

Van de Ven, A. H. (1986). Central problems in the management of innovation. Management Science, 32, 590-607. doi:http://dx.doi.org/10.1287/mnsc.32.5.590

White, S. S., Mueller-Hanson, R. A., Dorsey, D. W., \& Pulakos, E. D. et al. (2005). Developing adaptive proficiency in special forces officers. Arlington: U.S. Army Research Institute for the Behavioral and Social Sciences. Retrieved from http://oai.dtic.mil/oai/oai?verb=getRecord\&metadataPrefix=html\&identifier=ADA43244 3

Yukl, G. A. \& Mahsud, R. (2010). Why flexible and adaptive leadership is essential. Consulting Psychology Journal, Practice and Research, 62(2), 81-93. doi: http://dx.doi.org/10.1037/a0019835

\section{Author Biographies}

Steven A. Boylan, Associate Professor, U.S. Army's Command and General Staff College, Department of Command and Leadership. Retired U. S. Army Colonel after 27 years of service. Doctoral student (ABD) in Organizational Leadership (Management), Univeristy of Phoenix. Previously published articles concerning the miltiary and the media, strategic communication, and leadership.

Kenneth A. Turner, Assistant Professor and Curriculum Developer, U.S. Army's Command and General Staff College, Department of Command and Leadership. Retired U. S. Army Colonel after 26 years of service. Doctoral student in American Colonial military history, Kansas State University. 